\title{
Deleterious effects of plant cystatins against the banana weevil Cosmopolites sordidus
}

Andrew Kiggundu and Josephine Muchwezi

Forestry and Agricultural Biotechnology Institute, University of Pretoria, Pretoria, South Africa

Christell Van der Vyver and Altus Viljoen

Institute for Plant Biotechnology and Department of Plant Pathology, Stellenbosch University,

Matieland, South Africa

Juan Vorster, Urte Schlüter and Karl Kunert *

Forestry and Agricultural Biotechnology Institute, University of Pretoria, Pretoria, South Africa

Dominique Michaud *

Département de Phytologie, Université Laval, Québec, Canada

Running title: Cystatins against the banana weevil

* Correspondence to: Fax: +27 124203960 (K. Kunert) or +1 4186567856 (D. Michaud).

E-mail addresses: karl.kunert@fabi.up.ac.za (K. Kunert) or dominique.michaud@fsaa.ulaval.ca (D. Michaud). 
The general potential of plant cystatins for the development of insect-resistant transgenic plants still remains to be established given the natural ability of several insects to compensate for the loss of active cysteine proteases following inhibitor ingestion. Here we assessed the potential of cystatins for the development of banana lines resistant to the banana weevil Cosmopolites sordidus, a major pest of banana and plantain in Africa. Protease inhibitory assays were first conducted with protein and methylcoumarin (MCA) peptide substrates to measure the inhibitory efficiency of different cystatins in vitro, followed by a diet bioassay with cystatin-infiltrated banana stem disks to monitor the impact of two plant cystatins, oryzacystatin I (OC-I, or OsCYS1) and papaya cystatin (CpCYS1), on the overall growth rate of young weevil larvae. As observed earlier for other Coleoptera, banana weevils produce a variety of proteases for dietary protein digestion, including in particular Z-Phe-Arg-MCA-hydrolyzing (cathepsin L-like) and Z-Arg-ArgMCA-hydrolyzing (cathepsin B-like) proteases active in mildly acidic conditions. Both enzyme populations were sensitive to the diagnostic cysteine protease inhibitor E-64 and to different plant cystatins including OsCYS1. In line with these broad inhibitory effects of cystatins, OsCYS1 and CpCYS1 caused an important growth delay in young larvae developing for 10 days in cystatininfiltrated banana stem disks. These promising results, which illustrate the natural susceptibility of C. sordidus to plant cystatins, are discussed in the light of current genomic data on coleopteran cysteine cathepsins and recent hypotheses suggesting a key role for digestive cathepsin B-like enzymes as a determinant for resistance or susceptibility to plant cystatins in Coleoptera.

Keywords: Banana weevil (Cosmopolites sordidus); banana (Musa spp.); cathepsin B-like proteases; cysteine cathepsins; plant cystatins; oryzacystatin I 


\section{INTRODUCTION}

The banana weevil Cosmopolites sordidus (Germar) (Coleoptera: Curculionidae) is an insect pest of considerable importance in Africa, associated with the rapid decline of banana and plantain plantations (Gold, 1999a, 2000; Swennen and Vuylsteke, 2001; Gold et al., 2005). At the adult stage, banana weevil females deposit their eggs inside host plant tissues, at the base of the pseudostem or on an exposed corm. On hatching, the larvae tunnel through the corm to feed and develop, where they damage tissues, compromise water and mineral uptake, and weaken the colonized organs. Banana weevil infestations cause important losses in the field by a direct negative impact on harvestable bunch weight and a weakening effect on infested organs causing plant toppling during windstorms (Sengooba, 1986; Rukazambuga et al., 1998).

Banana weevil control in Africa relies essentially on cultural and sanitation practices such as the use of clean planting material, the systematic trapping of adult weevils to prevent population build-up, and the removal of plant residues serving as potential breeding grounds (Gold, 2000; Gold et al., 2002). High labour input and material requirements, however, often represent limiting factors for the effective implementation of sanitation practices in banana plantations, which makes it essential to develop complementary protection strategies (Gold, 1998; Gold et al., 2001). As for other staple crops, commercial insecticides have been considered to control insect populations, but the general adoption of these compounds in small-scale subsistence farming systems such as most banana plantations in Africa is hardly feasible from a socioeconomic standpoint, and potentially inefficient owing to the rapid development of genetic resistance in target weevil populations (Collins et al., 1991; Gold et al., 1999b). Biological control agents have also been considered for banana weevil control, but the actual effectiveness of biocontrol tools in field situations remains to be established (Paparu et al., 2008). 
At this point, the most straightforward way to prevent banana weevil infestations likely resides in the introduction of insect resistance in the banana genome (Kiggundu et al., 2003a). The sterile status of most banana varieties makes it unpractical to establish conventional crossbreeding programmes with elite cultivars, despite the wide diversity of potentially useful traits in the banana germplasm worldwide (Kiggundu et al., 2003b; Heslop-Harrison and Schwarzacher, 2007). By contrast, significant progress has been made in recent years towards the genetic transformation and in vitro regeneration of commercial banana and plantain varieties (Pérez Hernandez et al., 2006; Pommerrenig et al., 2006; Khanna et al., 2007), paving the way to the development of insectresistant transgenic banana lines. A number of recombinant proteins with pesticidal, antidigestive or antifeedant properties have been identified or devised over the years for the development of herbivorous pest-resistant crops by genetic transformation (Carlini and Grossi-de-Sá, 2002; Christou et al., 2006; Gatehouse, 2008; Zhu-Salzman et al., 2008). An engineered version of the rice cysteine protease inhibitor oryzacystatin I (OC-I) (Urwin et al., 1995) was shown, notably, to confer nematode resistance in transgenic banana lines genetically transformed with the corresponding transgene sequence (Atkinson et al., 2004a).

Recombinant cystatins appear of particular interest for the design of pest-resistant transgenic crops intended to human use, given the absence of target cysteine proteases in the human gut and the negligible negative effects expected for these proteins in food products (Arai and Abe, 2000; Atkinson et al. 2004b). The potential of midgut cysteine proteases as relevant targets for the control of coleopteran plant pests has also been underlined recently (Tribolium Genome Sequencing Consortium, 2008), considering the diversity of gene coding sequences for cysteine cathepsins in the recently described genome of the coleopteran herbivore Tribolium castaneum (Wang et al., 2007), the widespread occurrence of these enzymes among herbivorous 
Coleoptera (Murdock et al., 1987) and the detrimental effects of the broad-spectrum inhibitor of papain-like cysteine proteases, trans-epoxysuccinyl-L-leucylamido-(4-guanidino) butane (E-64), on growth and development of several coleopteran herbivores (e.g. Murdock et al., 1988; Bolter and Latoszek-Green, 1997; Fabrick et al., 2002). In this study, we assessed the potential of OC-I and other plant cystatins as possible tools for the production of transgenic banana lines resistant to the banana weevil. Several papers have been published assessing the effectiveness of plant cystatins against herbivorous Coleoptera, with conclusive results in some cases (Leplé et al., 1995; Kuroda et al., 1996; Lecardonnel et al., 1999; Koiwa et al., 2000; Alvarez-Alfageme et al. 2007; Ninkovic et al., 2007) but disappointing results in other cases owing to the ability of the target insects to readily elude or even counteract the antidigestive effects of natural or recombinant inhibitors (e.g. Girard et al., 1998a,b; Cloutier et al., 1999, 2000; Zhu-Salzman et al., 2003; Gruden et al., 2003, 2004; Ahn et al., 2004, 2007; Oppert et al., 2005; Koo et al., 2008). Here we document the broad inhibitory effects of plant cystatins against midgut cysteine cathepsins of the banana weevil, and the detrimental effects of these proteins on larval growth using a novel bioassay set-up with cystatin-infiltrated banana tissues.

\section{MATERIALS AND METHODS}

\section{Banana weevils}

Adult banana weevils were collected from commercial banana (Musa sp.) plantations in the South African province of Kwazulu Natal. The weevils were maintained in greenhouse at room temperature in 10-L plastic containers kept moist with water, and provided with fresh banana stems for oviposition. The weevils were removed after two days to allow for the development of freshly laid eggs. Third and fourth instars for protease assays were collected by dissection of 
infected stems, and weighed individually before use or storage at $-20^{\circ} \mathrm{C}$. Newly hatched larvae for bioassays (see below) were produced with fresh eggs extracted from infected stems, after gently removing thin slices of outer tissue with a sharp paring knife. The eggs were washed quickly in $70 \%$ (v/v) ethanol, rinsed twice in distilled water, incubated at $25^{\circ} \mathrm{C}$ in the dark on sterile moistened filter paper, and placed in a sterile Petri dish for hatching.

\section{Midgut proteases}

Frozen larvae were thawed on ice and dissected in cold distilled water under a stereomicroscope to extract whole midguts. Midgut tissues were ground to a fine powder in liquid nitrogen, and homogenized in $150 \mathrm{mM} \mathrm{CaCl}_{2}$ in water containing $0.1 \%(\mathrm{v} / \mathrm{v})$ Triton $\mathrm{X}-100$, with $200 \mathrm{mg}$ of tissue per $\mathrm{mL}$ of extraction solution. The mixture was incubated on ice for $30 \mathrm{~min}$, and then centrifuged at $12000 \mathrm{~g}$ for $10 \mathrm{~min}$ to remove cellular debris and insoluble material. The supernatant was collected and the protein content adjusted to $1 \mathrm{mg} / \mathrm{ml}$ with extraction solution. Insect material for gelatinase zymography (see below) was homogenized directly in $100 \mu \mathrm{L}$ of gelatin-PAGE sample loading buffer (62.5 mM Tris- $\mathrm{HCl}(\mathrm{pH} 8.0), 2 \%(\mathrm{w} / \mathrm{v})$ sucrose and $0.001 \%$ (w/v) bromophenol blue) (Michaud et al., 1996a). Protein concentration in the extracts was determined using the Bio-Rad Protein Assay Kit ${ }^{\mathrm{TM}}$ (Bio-Rad, Mississauga ON, Canada), with bovine serum albumin as a protein standard. Protein samples were used immediately for in vitro assays, or stored at $-20^{\circ} \mathrm{C}$ until use.

\section{Protease substrates and inhibitors}

The protein and synthetic protease substrates azocasein, gelatin (porcine type A), Z-Arg-Arg-7amido-4-methylcoumarin-hydrochloride (Z-RR-MCA), Z-Phe-Arg- (Z-FR-) MCA, Z-Arg- (Z-R-) 
MCA and succinyl-Ala-Ala-Pro-Phe- (suc-AAPF-) MCA were purchased from Sigma (Oakville ON, Canada). The protease inhibitors bovine aprotinin, E-64, ethylenediamine tetraacetic acid (EDTA), phenylmethylsulfonyl fluoride (PMSF), soybean trypsin-chymotrypsin inhibitor (SBBI) and L-3-trans-(propylcarbamyl)oxirane-2-carbonyl)-L-isoleucyl-L-proline (CA-074) were also from Sigma. The cathepsin L inhibitor Z-Phe-Tyr $(t \mathrm{Bu})$-diazomethylketone (Z-FY-DMK) was from Calbiochem (San Diego CA, USA). Recombinant forms of OC-I (referred to as OsCYS1: Girard et al., 2007), oryzacystatin II (OC-II, or OsCYS2), corn cystatin II (CC-II, or ZmCYS2) and human stefin A were produced in Escherichia coli as glutathione $S$-transferase fusion proteins (Smith and Johnson, 1988), as described earlier (Michaud et al., 1994, 1996b; Brunelle et al., 2005).

OsCYS1 was also expressed as a histidine (His)-tagged protein using the 6x Histidine Tagging System ${ }^{\mathrm{TM}}$ (Qiagen, Mississauga ON, Canada), with the vector pAOCI-3 (Leplé et al., 1995) as a DNA template. An OsCYS1-encoding DNA fragment excised from pAOCI-3 by EcoRI/PstI treatment was first cloned between the EcoRI and PstI cloning sites of pBlueScript (Stratagene, La Jolla CA, USA), re-excised as a BamHI/KpnI fragment, and finally introduced in the expression vector $\mathrm{pQE31}$ (Qiagen), in frame with the poly-His tag. The resulting plasmid, pQOC-I, was introduced in Escherichia coli strain M15 for heterologous expression and purification of the (His) $)_{6}$ OsCYS1 fusion by nickel $\left(\mathrm{Ni}^{2+}\right)$ affinity chelation, according to the instructions of the provider (Qiagen). Papaya cystatin (CpCYS1) was cloned, expressed as a (His) $)_{6}$-tagged protein and purified by $\mathrm{Ni}^{2+}$ affinity chelation as described for OsCYS1, using the vector $\mathrm{p} B l C Y S 1$ as starting material and giving the vector $\mathrm{p} Q P C$ for (His) ${ }_{6}-C p C Y S 1$ heterologous expression. 


\section{Protease and protease inhibitory assays}

Protease activities were assayed in vitro with the colorimetric protein substrate azocasein and a number of MCA fluorigenic substrates specific to different protease families. Overall protease activity in the extracts was monitored with azocasein at different $\mathrm{pH}$ values as described earlier (Michaud et al., 1995a). The assay buffers were as follows: $100 \mathrm{mM}$ citrate phosphate for $\mathrm{pH} 4.0$ to $\mathrm{pH} 7.0 ; 100 \mathrm{mM}$ Tris- $\mathrm{HCl}$ for $\mathrm{pH} 7.5$ to $\mathrm{pH} 8.5$; and $100 \mathrm{mM}$ glycine for $\mathrm{pH} 9.0$ to $\mathrm{pH} 10.0$. In brief, $50 \mu \mathrm{L}$ of midgut extract (50 $\mu$ g protein) was mixed with $450 \mu \mathrm{L}$ of assay buffer containing 5 $\mathrm{mM}$ L-cysteine. After $10 \mathrm{~min}$ at $37^{\circ} \mathrm{C}, 500 \mu \mathrm{L}$ of $2 \%(\mathrm{w} / \mathrm{v})$ azocasein dissolved in assay buffer was added, and the whole mixture was incubated for $180 \mathrm{~min}$ at $37^{\circ} \mathrm{C}$. Proteolysis was stopped by adding $100 \mu \mathrm{L}$ of $10 \%(\mathrm{w} / \mathrm{v})$ cold trichloroacetic acid and incubating the whole mixture for $30 \mathrm{~min}$ at $4^{\circ} \mathrm{C}$. Residual azocasein was removed by centrifugation at $12000 \mathrm{~g}$ for $5 \mathrm{~min}$ at $4^{\circ} \mathrm{C}$. One $\mathrm{mL}$ of $1 \mathrm{~N} \mathrm{NaOH}$ was finally added to $1 \mathrm{~mL}$ of supernatant, and the absorbance was read at $440 \mathrm{~nm}$ using a Spectronic 1000 Plus spectrophotometer (Milton Roy, Rochester NY, USA). The $A_{440}$ of blanks, which consisted of complete mixtures incubated for $0 \mathrm{~min}$, was subtracted from each value. One unit of activity was defined as the amount of insect extract needed to produce an absorbance change of $1.0 \mathrm{~h}^{-1}$ in a $1-\mathrm{cm}$ cuvette. Each measure was repeated three times.

Substrate-specific protease activities were monitored with synthetic fluorigenic MCA substrates by the monitoring of substrate hydrolysis progress curves (Salvesen and Nagase, 1989). Cathepsin L-like, cathepsin B-like and aminopeptidase (cathepsin H-like) activities were detected in $100 \mathrm{mM}$ citrate phosphate buffer, $\mathrm{pH}$ 6.0, using the substrates Z-FR-MCA, Z-RR-MCA and ZR-MCA, respectively. Trypsin-like and chymotrypsin-like activities were detected in $50 \mathrm{mM}$ Tris$\mathrm{HCl}$ buffer, $\mathrm{pH} 8.0$, using the substrates Z-R-MCA and suc-AAPF-MCA, respectively. Proteolysis was allowed to proceed at $22^{\circ} \mathrm{C}$ with the substrate in large excess, after adding (or not) protease 
inhibitors in a minimal volume (Kiggundu et al., 2006). Activity levels were monitored using a Fluostar Galaxy fluorimeter (BMG, Offenburg, Germany), with excitation and emission filters of $360 \mathrm{~nm}$ and $450 \mathrm{~nm}$, respectively. Protease activity rates in the presence or absence of inhibitor were inferred from the slope of the progress curves. All measures were repeated three times.

\section{Gelatin SDS-PAGE}

The inhibitory potency of $O s C Y S 1, C p C Y S 1, S B B I$ and bovine aprotinin against banana weevil midgut proteinases was also monitored by submitting the protease:inhibitor complexes to mildlydenaturing (non-reducing) gelatin/SDS-PAGE (Michaud, 1998). The insect extracts (3 $\mu \mathrm{L}$, for 3 $\mu \mathrm{g}$ of protein) were incubated with excess amounts of protein inhibitors (25 $\mu \mathrm{g}$ of inhibitor in 5 $\mu \mathrm{L}$ ), or with $5 \mu \mathrm{L}$ of $50 \mathrm{mM}$ Tris- $\mathrm{HCl}, \mathrm{pH} 8.0$ (non-inhibited control) for $10 \mathrm{~min}$ at $37^{\circ} \mathrm{C}$ before electrophoresis. Protease (gelatinase) forms were visualized as clear bands against a Coomassie blue-stained background following electrophoresis (Michaud et al., 1996a).

\section{Diet bioassay}

A diet bioassay was devised for the monitoring of banana weevil larval growth in OsCYS1 and CpCYS1-infiltrated banana stem disks (Fig. 1). Inner stems, which form part of the fruit (bunch) stalk but run in the centre of the pseudo-stem from the bunch to the underground stem, were collected fresh in the greenhouse, cut into 1-cm thick disks (approx. $15 \mathrm{~g}$ fresh weight) and dipped into a $1 \%(\mathrm{v} / \mathrm{v})$ sorbic acid solution in water for $5 \mathrm{~min}$ at $60^{\circ} \mathrm{C}$ to prevent tissue oxidation and deterioration. The disks were used immediately for the bioassays or wrapped in polythene bags for storage at $4^{\circ} \mathrm{C}$. For disk infiltration, $2 \mathrm{ml}$ of $O s C Y S 1$ or $C p C Y S 1$ solution [corresponding to $10 \mathrm{mg}$ of cystatin] was placed in a clean, 5-cm diameter Petri dish. Three 4-cm long/1-mm thick plastic 
rods were placed in the Petri dish and one banana stem disk was placed on the rods. This allowed placing the disk just above the bottom of the dish and providing uniform contact with the solution. The complete set-up was placed in a vacuum desiccator attached to an SC100 Thermo Savant SpeedVac ${ }^{\mathrm{TM}}$ vacuum pump (Thermo Fisher Scientific, Waltham MA, USA) equipped with a Savant RT100 refrigerated condensation trap (Thermo Fisher Scientific). A vacuum was applied, until observing bubbling on both the surface of the tissue and the solution. The vacuum was then rapidly removed by unplugging using a conveniently placed tap plunger, causing rapid infiltration of the banana stem disk with the cystatin solution. The infiltrated stem disk was removed and placed on a filter paper in a clean Petri dish, and a newly hatched banana weevil larva was placed in a small hole made on the disk. The treated disks were stored in the dark at $25^{\circ} \mathrm{C}$, and the larvae dissected out and weighted after 10 days. Disks infiltrated with elution buffer were used as negative controls. Each treatment was repeated with 10 to 15 larvae and disks.

\section{RESULTS}

\section{Cysteine and serine proteases in the banana weevil midgut}

Protein and fluorigenic peptide substrates were used to characterize banana weevil midgut proteases and their interactions with different synthetic and natural protease inhibitors. Azocasein was first used as a general, non-specific protein substrate to draw an overview of major protease activities in the midgut as a function of $\mathrm{pH}$ (Fig. 2A). The highest peak of activity in reducing conditions was found at mildly acidic $\mathrm{pH}$ values, with maximal protein hydrolysis at $\mathrm{pH}$ 6.5. A second, minor peak was detected at $\mathrm{pH} 8.5$, in line with Montesdeoca et al. (2005) reporting the occurrence of trypsin- and chymotrypsin-like serine proteases in larval midgut extracts. Azocasein hydrolysis at $\mathrm{pH}$ 6.5, detected at similar specific protein levels in larval and adult extracts (Fig. 
2B), was weakly sensitive to the serine protease inhibitor PMSF in reducing conditions (Fig. 2C). By contrast, the papain-like cysteine protease inhibitor E-64 strongly inhibited most protease activity in the same conditions (Fig. 2C), suggesting the predominance of cysteine (endo)proteases in the digestive tract of banana weevil larvae.

Methylcoumarin fluorigenic substrates were used to characterize protease activities in a more specific way, and to assess their sensitivity to different proteinaceous cysteine- and serine-type inhibitors (Fig. 3). Proteases active at pH 6.5 readily hydrolyzed the substrates Z-FR-MCA, Z-RRMCA and, to a lesser extent, R-MCA (Fig. 3A), suggesting the presence of cathepsin L-like, cathepsin B-like and aminopeptidase (cathepsin H-like) activities in larval extracts, as observed earlier for a number of coleopteran insects (e.g. Thie and Houseman, 1990; Michaud et al., 1993; Bown et al., 2004; Montesdeoca et al., 2005; Vinokurov et al., 2006a,b; Prabhakar et al., 2007). Trypsin- and chymotrypsin-like serine proteases hydrolyzing, respectively, Z-R-MCA and succinyl-AAPF-MCA were detected at $\mathrm{pH} 8.5$ (Fig. 3A) but merely detectable at $\mathrm{pH} 6.5$ (not shown), which points again to the presence of serine proteinases in the midgut extracts, as also reported for other Coleoptera predominantly relying on cysteine proteases for dietary protein digestion (e.g. Novillo et al., 1997; Vinokurov et al., 2006a,b; Prabhakar et al., 2007).

\section{Cystatin-sensitive cathepsins in the banana weevil midgut}

As expected, the broad-spectrum inhibitor of cysteine cathepsins E-64 inhibited most Z-FR-MCAand Z-RR-MCA-hydrolyzing proteases (Fig. 3B), compared to PMSF inhibiting most suc-AAPFMCA-hydrolyzing chymotrypsin-like proteinases and a significant fraction of Z-R-MCAhydrolyzing, trypsin-like proteinases (Fig. 3C). Confirming the occurrence of cathepsin L-like activity, the irreversible inhibitor Z-FY-DMK, specific to cathepsin L-like enzymes (Shaw et al., 
1993), inhibited Z-FR-MCA-hydrolyzing enzymes while inhibiting only a small fraction of the ZRR-MCA-hydrolyzing enzymes (Fig. 3B). By contrast, the E-64 derivative CA-074, specific to cathepsin B-like enzymes (Murata et al., 1991), showed no inhibitory activity against most Z-RRMCA- and Z-FR-MCA-hydrolyzing enzymes (Fig. 3B), as also reported earlier for midgut cysteine cathepsins of the Western corn rootworm Diabrotica virgifera (Bown et al., 2004). Unlike cysteine-type inhibitors (not shown), the potent trypsin inhibitor bovine aprotinin inhibited most trypsin-like and some chymotrypsin-like activities in the extracts, compared to the soybean Bowman-Birk (trypsin-chymotrypsin) inhibitor completely inactivating both Z-R-MCA- and sucAAPF-MCA-hydrolyzing proteinases (Fig. 3C). Similar to E-64, human stefin A and different plant cystatins including OsCYS1 inhibited an important fraction of the activity detected with the Z-FR-MCA and Z-RR-MCA substrates (Fig. 3B). Overall, the well-documented preference of coleopteran cathepsin L-like enzymes for Z-FR-MCA despite the Z-RR-MCA-hydrolyzing activity of some isoforms (Bown et al., 2004; Cristofoletti et al., 2005), the specificity of cathepsin B-like enzymes for Z-RR-MCA (Mort, 1998), and the differential inhibitory effects of Z-FY-DMK and human stefin A against banana weevil Z-FR- and Z-RR- hydrolyzing proteinases (Student $t$-test; $P<0.01$ ) (Fig. 3B) suggest the occurrence of cathepsin L-like and cathepsin B-like proteinase populations in the banana weevil midgut, both sensitive to E-64 and cystatins but exhibiting distinct preferences for the Z-FR-MCA and Z-RR-MCA substrates.

\section{Deleterious effects of plant cystatins against banana weevil larvae}

Dose-response protease inhibitory assays and gelatin/SDS-PAGE zymography were carried out with $O s C Y S 1$ and papaya cystatin $(C p C Y S 1)$ to estimate the inhibitory potency of different plant cystatins against banana weevil Z-FR-MCA- and gelatin-hydrolyzing cysteine cathepsins (Fig. 4). 
The two cystatins were expressed in E. coli as His-tagged proteins and purified under a stable form by immobilized metal $\left(\mathrm{Ni}^{2+}\right)$ affinity chromatography (Fig. 4A, inset gel). $I C_{50}$ values - i.e. the amount of inhibitor needed for 50\% inhibition- of 3.7 and $15.2 \mathrm{nM}$ were calculated, respectively, for the inhibition of cathepsin L-like proteinases by OsCYS1 and CpCYS1 under our assay conditions (Fig. 4A), which suggests a stronger inhibitory effect of the first inhibitor at low concentrations. The higher potency of OsCYS1 was also inferred by submitting the OsCYS1: and CpCYS1:weevil proteinase complexes to gelatin/SDS-PAGE in non-reducing conditions (Fig. 4B). Out of five gelatinases detected on the zymograms (referred to as proteinases P1 to P5), two (P1 and P2) were completely inhibited by OsCYS1 following electrophoresis in the presence of SDS, indicating a high stability for the OsCYS1:P1 and OsCYS1:P2 complexes, with $K_{\mathrm{i}}$ values presumably in the nanomolar or subnanomolar range (Michaud et al., 1996a). CpCYS1 also caused an important loss of P1 and P2 activity, but part of the inhibition was restored following electrophoresis, which suggests a weaker inhibitory effect against the two enzymes and $K_{\mathrm{i}}$ values in the $[10,100]$ nanomolar range for the $C p C Y S 1: P 1$ and $C p C Y S 1: P 2$ complexes (Michaud et al., 1996a).

A diet bioassay was conducted with banana weevil larvae and cystatin-infiltrated banana stem disks (see Fig. 1) to measure the impact of OsCYS1 and CpCYS1 on banana weevil larval growth (Fig. 5). As shown on Fig. 5A, larvae provided with cystatin-infiltrated stems were dramatically affected after 10 days, compared to larvae provided with control, cystatin-free material. No mortality due to cystatin ingestion was observed over the period assessed, but early larval growth expressed as body weight gain per day was significantly reduced by either cystatins (Fisher's LSD test; $P<0.01$ ), with measured growth rates of 0.25 to $0.35 \mathrm{mg} /$ day compared to 1.1 mg/day for larvae fed the control diet (Fig. 5B). Comparable growth decreases of about $70 \%$ 
relative to the controls were observed for the two cystatins under our experimental conditions $(P>$ 0.05), despite the stronger inhibitory potency of OsCYS1 against Z-FR-MCA-hydrolyzing enzymes (see Fig. 4).

\section{DISCUSSION}

Despite some promising developments (Leplé et al., 1995; Kuroda et al., 1996; Koiwa et al., 2000; Liu et al., 2004; Alvarez-Alfageme et al., 2007; Ninkovic et al., 2007), the general usefulness of plant cystatins for the control of coleopteran pests still remains to be established. These insects have developed over time effective strategies to elude the inhibitory effects of plant protease inhibitors, involving the use of complex digestive protease systems with proteases from different mechanistic classes acting in a complementary, coordinated manner (Brunelle et al., 1999; Hernandez et al., 2003; Gruden et al., 2003; Vinokurov et al., 2006a,b; Prabhakar et al., 2007); the over-expression of target proteases following cystatin ingestion to outnumber the inhibitory proteins (Cloutier et al., 2000; Ahn et al., 2004); the constitutive or diet-induced expression of cysteine cathepsins weakly sensitive to the ingested cystatin, the so-called 'cystatin-insensitive proteases' (Michaud et al., 1993, 1995a,b; Girard et al., 1998a; Cloutier et al., 1999, 2000; ZhuSalzman et al., 2003; Brunelle et al., 2004; Gruden et al., 2004; Liu et al., 2004; Koo et al., 2008); the over-expression of proteases from alternative mechanistic classes following cystatin ingestion (Zhu-Salzman et al., 2003; Brunelle et al., 2004; Rivard et al., 2004; Oppert et al., 2005); and the degradation of defensive protease inhibitors using non-target, insensitive proteases (Michaud et al., 1995b; Girard et al., 1998b; Giri et al., 1998; Gruden et al., 2003; Zhu-Salzman et al., 2003). Taking this into account, the aim of the present study was to assess the possible detrimental effects of plant cystatins against the banana weevil $C$. sordidus, and to interpret these effects in the light 
of their inhibitory spectrum against cysteine cathepsin activities eventually detected in midgut extracts. Protease inhibitory assays were first conducted to measure the inhibitory efficiency of different cystatins in vitro, followed by a diet bioassay with cystatin-infiltrated banana stem disks to visualize the impact of two plant cystatins, OsCYS1 and CpCYS1, on the overall growth rate of young larvae.

Similar to other successful examples (e.g. Zhao et al., 1996; Koiwa et al., 2000; Liu et al., 2004; Alvarez-Alfageme et al., 2007; Ninkovic et al., 2007), our data indicate a dramatic negative impact of plant cystatins on larval growth, associated with the presence of cystatin-sensitive cysteine cathepsins in midgut extracts. As suggested from studies reporting detrimental effects for the broad-spectrum inhibitor of papain-like proteases E-64 against Coleoptera, these negative effects of $O s C Y S 1$ and $C p C Y S 1$ were likely the result of a broad sensitivity of the insect digestive cathepsins to the ingested inhibitors. The negative effects of E-64 on growth and fecundity of several coleopteran species, including cystatin-resistant insects such as the Colorado potato beetle Leptinotarsa decemlineata (Bolter and Latoszek-Green, 1997) and the cowpea weevil Callosobruchus maculatus (Murdock et al., 1988), were systematically associated with a broadspectrum inhibition of cysteine proteases in midgut extracts (Michaud et al., 1993; Fabrick et al., 2002; Kim and Mullin, 2003). By contrast, the reported inefficiency of plant cystatins against a number of Coleoptera was typically associated with the presence of cystatin-insensitive cysteine proteases, thought to help the target insects compensating for the loss of sensitive protease activities following cystatin intake (Cloutier et al., 1999, 2000; Zhu-Salzman et al., 2003; Gruden et al., 2003, 2004). In line with previous studies reporting detrimental effects for cystatins or other plant cysteine-type inhibitors against some coleopteran species (Zhao et al., 1996; Koiwa et al., 2000; Fabrick et al., 2002), the negative effects of OsCYS1 and CpCYS1 against the banana 
weevil were correlated with a broad inhibitory spectrum of the two cystatins against Z-FR-MCA(cathepsin L-like) and Z-RR-MCA-hydrolyzing (cathepsin B-like) cysteine proteases in midgut extracts, comparable to the overall inhibitory effect of E-64 against the same enzymes. Our data support, in sum, the hypothesis of a close relationship between the inhibitory spectrum of plant cystatins against E-64-sensitive cysteine proteases in midgut extracts and the potential of these inhibitors as effective candidates for the development of transgenic plant lines resistant to coleopteran pests.

The detection of cathepsin L-like and cathepsin B-like activities in banana weevil midgut extracts is not surprising considering the prevalence and numerical importance of cathepsin $\mathrm{L}$ and cathepsin B coding sequences in the recently described genome of T. castaneum (Tribolium Genome Sequencing Consortium, 2008), a coleopteran herbivore of the same evolutionary clade (Hunt et al., 2007). On the other hand, the occurrence of cathepsin B variants sensitive to cystatins in the midgut of the banana weevil (Fig. 3B) [and other cystatin-susceptible insects (Bown et al., 2004)] is somewhat intriguing since these enzymes were identified as possible key players in the resistance of Coleoptera to dietary cystatins (Michaud et al., 1993; Cloutier et al., 2000; Goulet et al., 2008; Koo et al., 2008). Unlike other proteases of the papain family, cathepsin B and cathepsin B-like homologues bear an extra structural element, the 'occluding loop', that physically hinders the substrate binding cleft and prevents free access to the inhibitory loops of large competitive inhibitors such as cystatins (Musil et al., 1991; Illy et al., 1997). In agreement with these structural inferences, a bacterially expressed variant of CmCatB1, a midgut cathepsin B-like enzyme synthesized de novo in the cowpea weevil C. maculatus challenged with dietary cystatins (Liu et al., 2004; Moon et al., 2004), was shown recently to bear an occluding loop-like structure, slightly 
shorter than the occluding loop of human cathepsin B but long enough to cause steric hindrance in the active site cleft and prevent inhibition by cystatins (Koo et al., 2008).

At the present stage, a possible explanation for the broad-spectrum inhibition of coleopteran cysteine cathepsins by plant cystatins might be the predominance of cathepsin L-like enzymes in midgut extracts, including some forms able to cleave both the Z-RR-MCA and Z-FR-MCA substrates (see Bown et al. 2004 and Cristofoletti et al., 2005). An alternative explanation would be the existence of two cathepsin B populations in the midgut exhibiting differential sensitivity to cystatin inhibition. Supporting this hypothesis, a preliminary assessment of coleopteran cathepsin B coding sequences from the National Center for Biotechnology Information database (www.ncbi.nlm.nih.gov) and a close look at cysteine cathepsin sequences in the T. castaneum BeetleBase genome database (Wang et al., 2007) reveal the presence of two cathepsin B subgroups in Coleoptera, differing in the length of their occluding loop (Fig. 6). A first group includes cathepsin B variants with an occluding loop structurally similar to the occluding loop of human cathepsin B. The second group includes variants with a shorter loop, similar in length to the occluding loop of M1, an engineered loop-truncated form of human cathepsin B showing dramatically increased sensitivity to human cystatin C (Illy et al., 1997). From a functional viewpoint, this observation could explain the recently observed occurrence of two cathepsin B populations in midgut extracts of the cystatin-resistant Colorado potato beetle L. decemlineata, dramatically differing in their sensitivity to engineered variants of the tomato cystatin SlCYS8 (Goulet et al., 2008). It could also explain the negligible susceptibility of cystatin-sensitive Z-RRMCA-hydrolyzing enzymes of the banana weevil (this study) and the Western corn rootworm (Bown et al., 2004) to the diagnostic cathepsin B inhibitor CA-074, which exerts its inhibitory 
effect by a specific interaction with conserved histidine residues present on the long occluding loops (Yamamoto et al., 1997) but absent from the shorter loops (Fig. 6).

Additional empirical data are needed at the physiological and structural levels to document further the role of cathepsin B variants as key determinants for the resistance or susceptibility to plant cystatins in different herbivorous Coleoptera. Additional work is also required to compare the antidigestive potential of different plant cystatins against the banana weevil. Our bioassays with $O s C Y S 1$ and $C p C Y S 1$ were conducted with excess concentrations of inhibitor, estimated at $\sim 0.6 \mathrm{mg} / \mathrm{g}$.fresh weight of infiltrated stem disk after re-extraction (not shown). Such concentrations would represent accumulation rates reaching $\sim 2 \%$ of leaf soluble proteins in tissues of transgenic banana lines, compared to lower rates of $0.1-1.0 \%$ typically observed in cystatinexpressing transgenic plants (Cloutier et al., 2000; Van der Vyver et al., 2003). In practice, a strong inhibitory potency of the protease inhibitor selected is critical for an effective inhibition effect, as it directly determines the minimal amount of recombinant inhibitor required in the modified host plant to provide sufficient pesticidal effects (De Leo et al., 1998; Goulet et al., 2008). On this basis, the strong binding activity of OsCYS1 against cysteine cathepsins of the banana weevil compared to $C p C Y S 1$ (see Fig. 4) would likely make this cystatin an interesting starting point for the development of transgenic banana lines resistant to this insect pest.

\section{ACKNOWLEDGMENTS}

This work was supported by the National Research Foundation of South Africa, and by the Natural Science and Engineering Research Council of Canada. We are grateful to the South African Banana Grower's Association for providing banana weevils and fresh banana material. A. Kiggundu was the recipient of a graduate fellowship from the Rockefeller Foundation. 


\section{LITERATURE CITED}

Ahn J-E, Lovingshimer MR, Salzman RA, Presnail JK, Lu AL, Koiwa H, Zhu-Salzman K. 2007. Cowpea bruchid Callosobruchus maculatus counteracts dietary protease inhibitors by modulating propeptides of major digestive enzymes. Insect Mol Biol 16:295-304.

Ahn J-E, Salzman RA, Braunagel SC, Koiwa H, Zhu-Salzman K. 2004. Functional roles of specific bruchid protease isoforms in adaptation to a soybean protease inhibitor. Insect Mol Biol 13:649-657.

Alvarez-Alfageme F, Martinez M, Pascual-Ruiz S, Castanera P, Diaz I, Ortego F. 2007. Effects of potato plants expressing a barley cystatin on the predatory bug Podisus maculiventris via herbivorous prey feeding on the plant. Transgenic Res 16:1-13.

Arai S, Abe K. 2000. Cystatin-based control of insects, with special reference to oryzacystatin. In: Michaud D, editor. Recombinant protease inhibitors in plants. Georgetown TX: Landes Bioscience. p. 27-42.

Atkinson HJ, Grimwood S, Johnston K, Green J. 2004a. Prototype demonstration of transgenic resistance to the nematode Radopholus similes conferred on banana by a cystatin. Transgenic Res 13:135-142.

Atkinson HJ, Johnston KA, Robbins M. 2004b. Prima facie evidence that a phytocystatin for transgenic plant resistance to nematodes is not a toxic risk in the human diet. J Nutr 134:431434.

Bolter CJ, Latoszek-Green M. 1997. Effect of chronic ingestion of the cysteine proteinase inhibitor, E-64, on Colorado potato beetle gut proteinases. Entomol Exp Applic 83:295-303. 
Bown DP, Wilkinson HS, Jongsma MA, Gatehouse JA. 2004. Characterisation of cysteine proteinases responsible for digestive proteolysis in guts of larval western corn rootworm (Diabrotica virgifera) by expression in the yeast Pichia pastoris. Insect Biochem Mol Biol $34: 305-320$.

Brunelle F, Girard C, Cloutier C, Michaud D. 2005. A hybrid, broad-spectrum inhibitor of Colorado potato beetle aspartate and cysteine digestive proteinases. Arch Insect Physiol Biochem 60:20-31.

Brunelle F, Cloutier C, Michaud D. 2004. Colorado potato beetles compensate for tomato cathepsin D inhibitor expressed in transgenic potato. Arch Insect Biochem Physiol 55:103-113.

Brunelle F, Nguyen-Quoc B, Cloutier C, Michaud D. 1999. Protein hydrolysis by Colorado potato beetle, Leptinotarsa decemlineata, digestive proteases: the catalytic role of cathepsin D. Arch Insect Biochem Physiol 42:88-98.

Carlini CR, Grossi-de-Sá MF. 2002. Plant toxic proteins with insecticidal properties. A review on their potentialities as bioinsecticides. Toxicon 40:1515-1539.

Christou P, Capell T, Kohli A, Gatehouse JA, Gatehouse AMR. 2006. Recent developments and future prospects in insect pest control in transgenic crops. Trends Plant Sci 11:302-308.

Cloutier C, Fournier M, Jean C, Yelle S, Michaud D. 1999. Growth compensation and faster development of Colorado potato beetle (Coleoptera: Chrysomelidae) feeding on potato foliage expressing oryzacystatin I. Arch Insect Biochem Physiol 40:69-79.

Cloutier C, Jean C, Fournier M, Yelle S, Michaud D. 2000. Adult Colorado potato beetles, Leptinotarsa decemlineata compensate for nutritional stress on oryzacystatin I-transgenic potato plants by hypertrophic behaviour and over-production of insensitive proteinases. Arch Insect Biochem Physiol 44:69-81. 
Collins PJ, Treverrow NL, Lambkin TM. 1991. Organophosphorous insecticide resistance and its management in the banana weevil borer, Cosmopolites sordidus Germar (Coleoptera: Curculionidae) in Australia. Crop Protect 10:215-221.

Corpet F. 1988. Multiple sequence alignment with hierarchical clustering. Nucleic Acids Res 16:10881-10890.

Cristofoletti PT, Ribeiro AF, Terra WR. 2005. The cathepsin L-like proteinases from the midgut of Tenebrio molitor larvae: sequence, properties, immunocytochemical localization and function. Insect Biochem Mol Biol 35:883-901.

De Leo F, Bonadé-Bottino MA, Ceci LR, Gallerani R, Jouanin L. 1998. Opposite effects on Spodoptera littoralis larvae of high expression level of a trypsin proteinase inhibitor in transgenic plants. Plant Physiol 118:997-1004.

Fabrick J, Behnke C, Czapla T, Bala K, Rao AG, Kramer KJ, Reeck GR. 2002. Effects of a potato cysteine proteinase inhibitor on midgut proteolytic enzyme activity and growth of the southern corn rootworm, Diabrotica undecimpunctata howardi (Coleoptera: Chrysomelidae). Insect Biochem Mol Biol 32:405-415.

Gatehouse JA. 2008. Biotechnological prospects for engineering insect-resistant plants. Plant Physiol 136:881-887.

Girard C, Rivard D, Kiggundu A, Kunert K, Gleddie SC, Cloutier C, Michaud D. 2007. A multicomponent, elicitor-inducible cystatin complex in tomato, Solanum lycopersicum. New Phytol 173:841-851.

Girard C, Le Métayer M, Zaccomer B, Bartlet E, Williams I, Bonadé-Bottino M, Pham-Delegue M-H, Jouanin L. 1998a. Growth stimulation of beetle larvae reared on a transgenic oilseed rape expressing a cysteine proteinase inhibitor. J Insect Physiol 44:263-270. 
Girard C, Le Métayer M, Bonadé-Bottino M, Pham-Delegue M-H, Jouanin L. 1998b. High level of resistance to proteinase inhibitors conferred by proteolytic cleavage in beetle larvae. Insect Biochem Mol Biol 28:229-237.

Giri AP, Harsulkar AM, Deshpande VV, Sainani MN, Gupta VS, Ranjekar PK. 1998. Chickpea defensive proteinase inhibitors can be inactivated by podborer gut proteinases. Plant Physiol 116:393-401.

Gold CS. 2000. Biology and integrated pest management of banana weevil, Cosmopolites sordidus (Germar). In: Molina AB, Roa VN and Maghuyop MAG, editors. Advancing banana and plantain R\&D in Asia and the Pacific, vol. 10. INIBAP-ASPNET. p. 28-33.

Gold CS. 1998. Banana weevil: ecology, pest status and prospects for integrated control with emphasis on East Africa. In: Saini SK, editor. Proceedings of a Symposium on Biological Control in Tropical Habitats: Third International Conference on Tropical Entomology. Nairobi (Kenya): ICIPE. p. 49-74.

Gold CS, Ragama PE, Coe R, Rukazambuga NDTM. 2005. Selection of assessment methods for evaluating banana weevil Cosmopolites sordidus (Coleoptera: Curculionidae) damage on highland cooking banana (Musa spp., genome group AAA-EA). Bull Entomol Res 95:115-123.

Gold CS, Okech SH, Nokoe S. 2002. Evaluation of pseudostem trapping as a control measure against banana weevil, Cosmopolites sordidus (Coleoptera: Curculionidae) in Uganda. Bull Entomol Res 92:35-44.

Gold CS, Peña JE, Karamura EB. 2001. Biology and integrated pest management of the banana weevil, Cosmopolites sordidus (Germar) (Coleoptera: Curculionidae). Integr Pest Manag Rev 6:79-155. 
Gold CS, Karamura EB, Kiggundu A, Bagamba F, Abera AMK. 1999a. Geographic shifts in highland cooking banana (Musa spp. group AAA-EA) production in Uganda. Int J Sustain Dev World Ecol 6:45-59.

Gold CS, Bagabe MI, Sendege R. 1999b. Banana weevil, Cosmopolites sordidus (Germar) (Coleoptera: Curculionidae): tests for suspected resistance to carbofuran and dieldrin in the Masaka District, Uganda. Afr Entomol 7:189-196.

Goulet M-C, Dallaire C, Vaillancourt L-P, Khalf M, Badri AM, Preradov A, Duceppe MO, Goulet C, Cloutier C, Michaud D. 2008. Tailoring the specificity of a plant cystatin toward herbivorous insect digestive cysteine proteases by single mutations at positively selected amino acid sites. Plant Physiol 146:1010-1019.

Gruden K, Kuipers AGJ, Guncar G, Slapar N, Strukelj B, Jongsma MA. 2004. Molecular basis of Colorado potato beetle adaptation to potato plant defence at the level of digestive cysteine proteinases. Insect Biochem Mol Biol 34:365-375.

Gruden K, Popovic T, Cimerman N, Krizaj I, Strukelj B. 2003. Diverse enzymatic specificities of digestive proteases, 'intestains', enable Colorado potato beetle larvae to counteract the potato defence mechanism. Biol Chem 384:305-310.

Hernandez CA, Pujol M, Alfonso-Rubi J, Armas R, Coll Y, Pérez M, Gonzalez A, Ruiz M, Castanera P, Ortego F. 2003. Proteolytic gut activities in the rice water weevil, Lissorhoptrus brevirostris Suffrian (Coleoptera: Curculionidae). Arch Insect Biochem Physiol 53:19-29.

Heslop-Harrison JS, Schwarzacher T. 2007. Domestication, genomics and the future of banana. Ann Bot 100:1073-1084.

Hunt T, Bergsten J, Levkanicova Z, Papadopoulou A, St. John O, Wild R, Hammond PM, Ahrens D, Balke M, Caterino MS, Gomez-Zurita J, Ribera I, Barraclough TG, Bocakova M, Bocak L, 
Vogler AP. 2007. A comprehensive phylogeny of beetles reveals the evolutionary origins of a superradiation. Science 318:1913-1916.

Illy C, Quraishi O, Wang J, Purisima E, Vernet T, Mort JS. 1997. Role of the occluding loop in cathepsin B activity. J Biol Chem 272:1197-1202.

Khanna HK, Paul J-Y, Harding RM, Dickman MB, Dale JL. 2007. Inhibition of Agrobacteriuminduced cell death by antiapoptotic gene expression leads to very high transformation efficiency of banana. Mol Plant-Microbe Interact 20:1048-1054.

Kiggundu A, Pillay M, Viljoen A, Gold C, Tushemereirwe W, Kunert K. 2003a. Enhancing banana weevil (Cosmopolites sordidus) resistance by genetic modification: A perspective. Afr J Biotechnol 2:563-569.

Kiggundu A, Gold CS, Labuschagne MT, Vuylsteke D, Louw S. 2003b. Levels of host plant resistance to banana weevil, Cosmopolites sordidus (Germar) (Coleoptera: Curculionidae), in African Musa germplasm. Euphytica 133:267-277.

Kiggundu A, Goulet M-C, Goulet C, Dubuc J-F, Rivard D, Benchabane M, Pépin G, van der Vyver C, Kunert K, Michaud D. 2006. Modulating the proteinase inhibitory profile of a plant cystatin by single mutations atpositively selected amino acid sites. Plant J 48:403-413.

Kim JH, Mullin CA. 2003. Impact of cysteine proteinase inhibition in midgut fluid and oral secretion on fecundity and pollen consumption of Western corn rootworm (Diabrotica virgifera virgifera). Arch Insect Biochem Physiol 52:139-154.

Koiwa H, Shade RE, Zhu-Salzman K, D'Urzo MP, Murdock LL, Bressan RA, Hasegawa PM. 2000. A plant defensive cystatin (soyacystatin) targets cathepsin L-like digestive cysteine proteinases (DvCALs) in the larval midgut of western corn rootworm (Diabrotica virgifera virgifera). FEBS Lett 471:67-70. 
Koo YD, Ahn J-E, Salzman RA, Moon J, Chi YH, Yun D-J, Lee SY, Koiwa H, Zhu-Salzman K. 2008. Functional expression of an insect cathepsin B-like counter-defence protein. Insect Mol Biol 17:235-245.

Kuroda M, Ishimoto M, Suzuki K, Kondo H, Abe K, Kitamura K, Arai S. 1996. Oryzacystatins exhibit growth-inhibitory and lethal effects on different species of bean insect pests, Callosobruchus chinensis (Coleoptera) and Riptortus clavatus (Hemiptera). Biosci Biotechnol Biochem 60:209-212.

Lecardonnel A, Chauvin L, Jouanin L, Beaujean A, Prevost G, Sangwan-Norreel B. 1999. Effect of rice cystatin I expression in transgenic potato on Colorado potato beetle larvae. Plant Sci 140:71-79.

Leplé J-C, Bonadé-Bottino M, Augustin S, Delplanque A, Dumanois Le Tân V, Pilate G, Cornu D, Jouanin L. 1995. Toxicity to Chrysomela tremulae (Coleoptera: Chrysomelidae) of transgenic poplars expressing a cysteine proteinase inhibitor. Mol Breed 1:319-326.

Liu Y, Salzman RA, Pankiw T, Zhu-Salzman K. 2004. Transcriptional regulation in southern corn rootworm larvae challenged by soyacystatin N. Insect Biochem Mol Biol 34:1069-1077.

Michaud D. 1998. Gel electrophoresis of proteolytic enzymes. Anal Chim Acta 372:173-185.

Michaud D, Cantin L, Raworth DA, Vrain TC. 1996a. Assessing the stability of cystatin/cysteine proteinase complexes using mildly-denaturing gelatin polyacrylamide gel electrophoresis. Electrophoresis 17:74-79.

Michaud D, Nguyen-Quoc B, Vrain TC, Fong D, Yelle S. 1996b. Response of digestive cysteine proteinases from the Colorado potato beetle (Leptinotarsa decemlineata) and the black vine weevil (Otiorynchus sulcatus) to a recombinant form of human stefin A. Arch Insect Biochem Physiol 31:451-464. 
Michaud D, Bernier-Vadnais N, Overney S, Yelle S. 1995a. Constitutive expression of digestive cysteine proteinase forms during development of the Colorado potato beetle, Leptinotarsa decemlineata Say (Coleoptera: Chrysomelidae). Insect Biochem Mol Biol 25:1041-1048.

Michaud D, Cantin L, Vrain TC. 1995b. Carboxy-terminal truncation of oryzacystatin II by oryzacystatin-insensitive insect digestive proteinases. Arch Biochem Biophys 322:469-474.

Michaud D, Nguyen-Quoc B, Yelle S. 1994. Production of oryzacystatins I and II in Escherichia coli using the glutathione $S$-transferase gene fusion system. Biotechnol Progr 10:155-159.

Michaud D, Nguyen-Quoc B, Yelle S. 1993. Selective inhibition of Colorado potato beetle cathepsin H by oryzacystatins I and II. FEBS Lett 331:173-176.

Montesdeoca M, Lobo MG, Casanas N, Camero A, Castanera P, Ortego F. 2005. Partial characterization of the proteolytic enzymes in the gut of the banana weevil, Cosmopolites sordidus, and effects of soybean Montesdeoca Kunitz trypsin inhibitor on larvae performance. Entomol Exp Applic 116:227-236.

Moon J, Salzman RA, Ahn J-E, Koiwa H, Zhu-Salzman K. 2004. Transcriptional regulation in cowpea bruchid guts during adaptation to a plant defence protease inhibitor. Insect Mol Biol $13: 283-291$.

Mort JS. 1998. Cathepsin B. In: Barrett AJ, Rawlings ND and Woessner JF, editors. Handbook of proteolytic enzymes. San Diego CA:Academic Press. p. 609-617.

Murata M, Miyashita S, Yokoo C, Tamai M, Hanada K, Hatayama K, Towatari T, Nikawa T, Katunuma N. 1991. Novel epoxysuccinyl peptides: selective inhibitors of cathepsin B in vitro. FEBS Lett 280:307-310.

Murdock LL, Shade RE, Pomeroy MA. 1988. Effects of E-64, a cysteine proteinase inhibitor on cowpea weevil growth, development, and fecundity. Environ Entomol 17:467-469. 
Murdock LL, Brookhart G, Dunn PE, Foard DE, Keley S, Kitch L. 1987. Cysteine digestive proteinases in Coleoptera. Comp Biochem Physiol B 87:783-787.

Musil D, Zucic D, Turk D, Engh RA, Mayr I, Huber R, Popovic T, Turk V, Towatari T, Katunuma N, Bode W. 1991. The refined 2.15-A X-ray crystal-structure of human liver cathepsin-B - The structural basis for its specificity. EMBO J 10:2321-2330.

Ninkovic S, Miljus-Dukic J, Radovic S, Maksimovic V, Lazarevic J, Vinterhalter B, Neskovic M, Smigocki A. 2007. Phytodecta fornicata Brüggemann resistance mediated by oryzacystatin II proteinase inhibitor transgene. Plant Cell Tissue Organ Cult 91:289-294.

Novillo C, Castanera P, Ortego F. 1997. Characterization and distribution of chymotrypsin-like and other digestive proteases in Colorado potato beetle larvae. Arch Insect Biochem Physiol 36:181-201.

Oppert B, Morgan TD, Hartzer K, Kramer KJ. 2005. Compensatory proteolytic responses to dietary proteinase inhibitors in the red flour beetle, Tribolium castaneum (Coleoptera: Tenebrionidae). Comp Biochem Physiol C 140:53-58.

Paparu P, Dubois T, Gold CS, Niere B, Adipala E, Coyne D. 2008. Screenhouse and field persistence of nonpathogenic endophytic Fusarium oxysporum in Musa tissue culture plants. Microb Ecol 55:561-568.

Pérez Hernandez JB, Remy S, Swennen R, Sagi L. 2006. Banana (Musa sp.). Meth Mol Biol 344:167-175.

Pommerrenig B, Barth I, Niedermeier M, Kopp S, Schmid J, Dwyer RA, McNair RJ, Klebl F, Sauer N. 2006. Common plantain. A collection of expressed sequence tags from vascular tissue and a simple and efficient transformation method. Plant Physiol 142:1427-1441. 
Prabhakar S, Chen M-S, Elpidina EN, Vinokurov KS, Smith CS, Marshall J, Oppert B. 2007. Sequence analysis and molecular characterization of larval midgut cDNA transcripts encoding peptidases from the yellow mealworm, Tenebrio molitor L. Insect Mol Biol 16:455-468.

Rivard D, Cloutier C, Michaud D. 2004. Colorado potato beetles show differential digestive compensatory responses to host plants expressing distinct sets of defense proteins. Arch Insect Biochem Physiol 55:114-123.

Rukazambuga NDTM, Gold CS, Gowen S. 1998. Yield loss in East African highland banana (Musa spp., AAA-EA group) caused by the banana weevil, Cosmopolites sordidus Germar. Crop Protect 17:581-589.

Sagi L, Panis B, Remy S, Schoofs H, De Smet K, Swennen R, Cammue BP. 1995. Genetic transformation of banana and plantain (Musa spp.) via particle bombardment. Biotechnology 13:481-485.

Salvesen G, Nagase H. 1989. Inhibition of proteolytic enzymes. In: Beynon RJ and Bond JS, editors. Proteolytic enzymes. A practical approach. New York:IRL Press. p. 83-104.

Sengooba T. 1986. Survey of banana pest problem complex in Rakai and Masaka Districts in Uganda. August 1986: Preliminary trip report. Namulonge (Uganda): Namulonge Research Station.

Shaw E, Mohanty S, Colic A, Stoka V, Turk V. 1993. The affinity labelling of cathepsin S with peptidyl diazomethyl ketones. Comparison with the inhibition of cathepsin L and calpain. FEBS Lett 334:340-342.

Smith DB, Johnson KS. 1988. Single-step purification of polypeptides expressed in Escherichia coli as fusions with glutathione $S$-transferase. Gene 67:31-40. 
Swennen R, Vuylsteke D. 2001. Banana Musa L. In: Raemaekers RH, editor. Crop Production in Tropical Africa. Brussels (Belgium): DGIC. p. 530-552.

Thie NM, Houseman JG. 1990. Identification of cathepsin B, D and H in the larval midgut of Colorado potato beetle, Leptinotarsa decemlineata Say (Coleoptera: Chrysomelidae). Insect Biochem 20:313-318.

Tribolium Genome Sequencing Consortium. 2008. The genome of the model beetle and pest Tribolium castaneum. Nature 452:949-955.

Urwin PE, Atkinson HJ, Waller DA, McPherson MJ. 1995. Engineered oryzacystatin I expressed in transgenic hairy roots confers resistance to Globodera pallida. Plant J 8:121-131.

Van der Vyver C, Schneidereit J, Driscoll S, Turner J, Kunert K, Foyer CH. 2003. Oryzacystatin I expression in transformed tobacco produces a conditional growth phenotype and enhances chilling tolerance. Plant Biotechnol J 1:101-112.

Vinokurov KS, Elpidina EN, Oppert B, Prabhakar S, Zhuzhikov DP, Dunaevsky YE, Belozersky MA. 2006a. Diversity of digestive proteinases in Tenebrio molitor (Coleoptera: Tenebrionae) larvae. Comp Biochem Physiol B 145:126-137.

Vinokurov KS, Elpidina EN, Oppert B, Prabhakar S, Zhuzhikov DP, Dunaevsky YE, Belozersky MA. 2006b. Fractionation of digestive proteinases from Tenebrio molitor (Coleoptera: Tenebrionae) larvae and role in protein digestion. Comp Biochem Physiol B 145:138-146.

Wang LJ, Wang S, Li Y, Paradesi MS, Brown SJ. 2007. Beetlebase: the model organism database for Tribolium castaneum. Nucl Acids Res 35:D476-D479.

Zhao Y, Botella MA, Subramanian L, Niu X, Nielsen SS, Bressan RA, Hasegawa PM. 1996. Two wound-inducible soybean cysteine proteinase inhibitors have greater insect digestive proteinase inhibitory activities than a constitutive homolog. Plant Physiol 111:1299-1306. 
Zhu-Salzman K, Luthe DS, Felton GA. 2008. Arthropod-inducible proteins: Broad spectrum defenses against multiple herbivores. Plant Physiol 146:852-858.

Zhu-Salzman K, Koiwa H, Salzman RA, Shade RE, Ahn J-E. 2003. Cowpea bruchid Callosobruchus maculatus uses a three-component strategy to overcome a plant defensive cysteine protease inhibitor. Insect Mol Biol 12:135-145. 


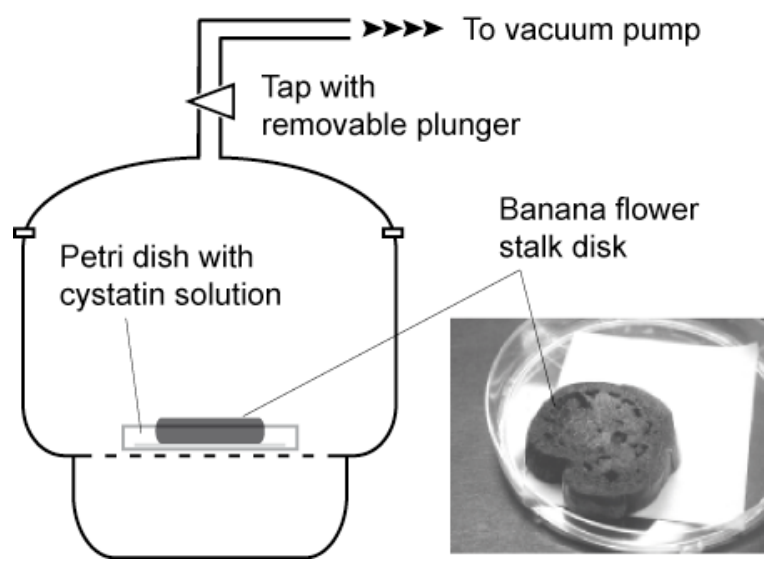

Figure 1. Experimental set-up for the monitoring of banana weevil larval growth in banana stem disks infiltrated with plant cystatins. The stem disks were first infiltrated with a cystatin solution using a vacuum pump (this figure), and then transferred in a Petri dish for larva inoculation and growth monitoring (see text for details). 

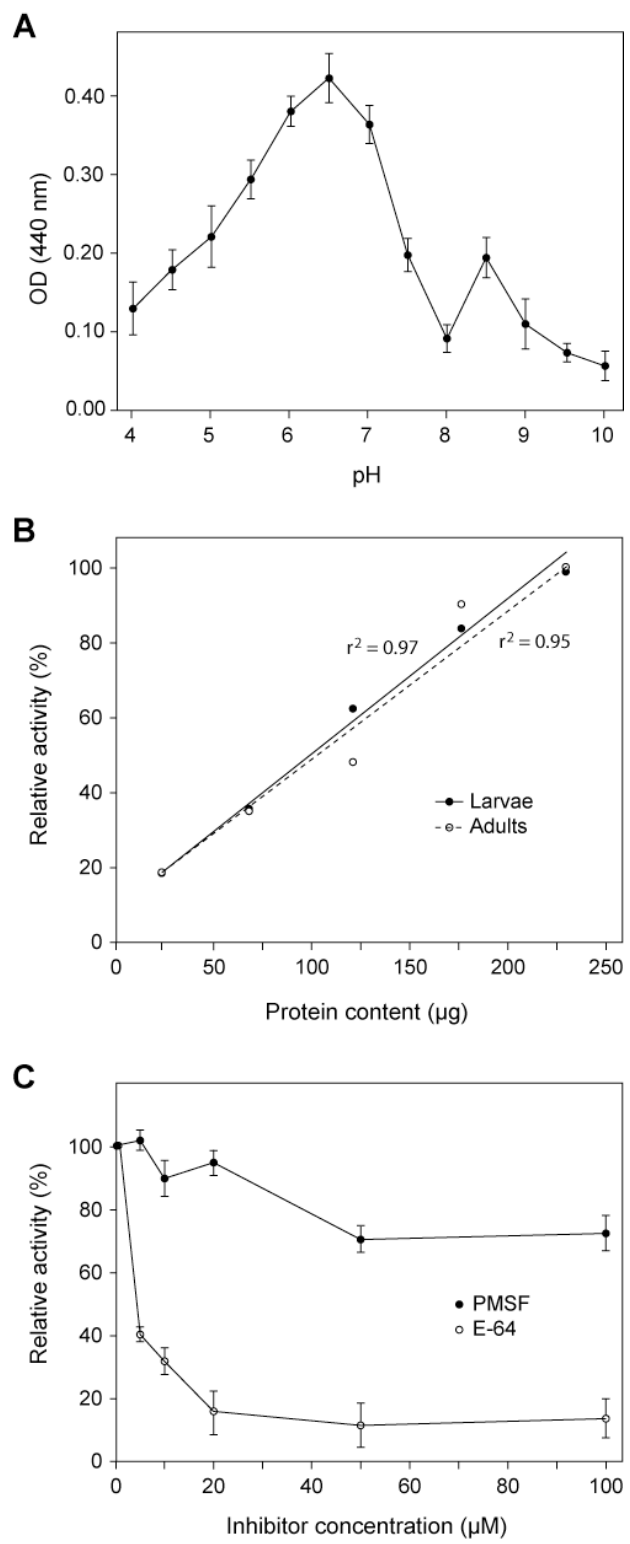

Figure 2. Proteinase (azocaseinase) activities in midgut protein extracts of the banana weevil. (A) Proteinase profile from $3^{\text {rd }}-/ 4^{\text {th }}$-instars larval extracts, as a function of $\mathrm{pH}$. Each datum is the mean of three independent values $\pm \mathrm{SE}$. (B) Specific proteinase activities in $3^{\text {rd }} / 4^{\text {th }}$-instars and adult extracts. Data are expressed as relative activities compared to the activity measured with $50 \mu \mathrm{g}$ of larval protein extract at $\mathrm{pH} 6.5$. Straight lines were fitted to the data by the leastsquares method. (C) Dose-response effects of the diagnostic protease inhibitors trans-epoxysuccinyl-L-leucylamido(4-guanidino) butane (E-64) and phenylmethylsulfonyl fluoride (PMSF) on midgut proteinases of $3^{\text {rd }}-/ 4^{\text {th }}-$ instars larvae active at $\mathrm{pH}$ 6.5. Data are expressed as relative activities compared to a non-inhibited control (100\%). Each datum is the mean of three independent values \pm SE. 


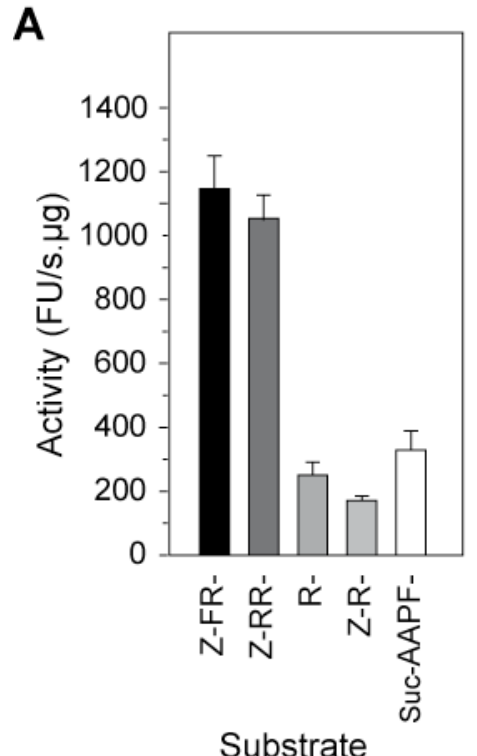

Substrate
B

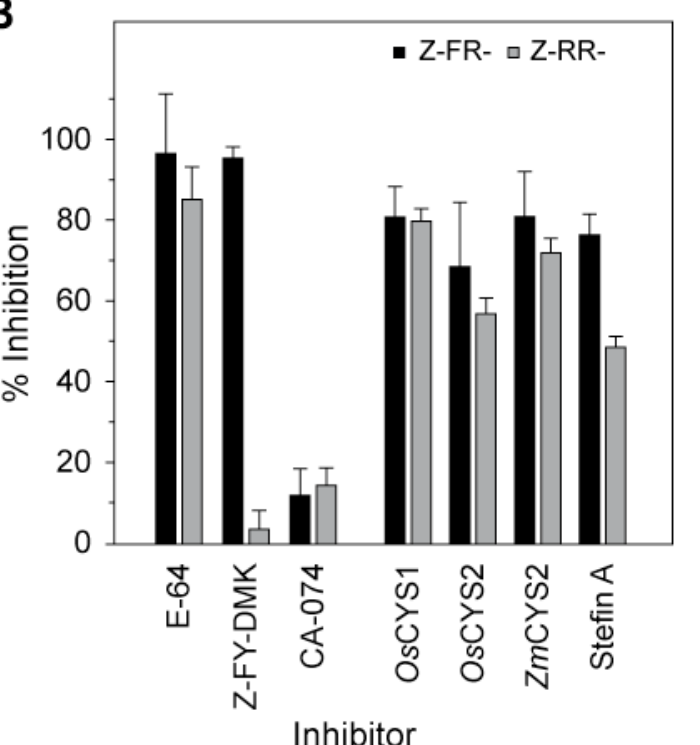

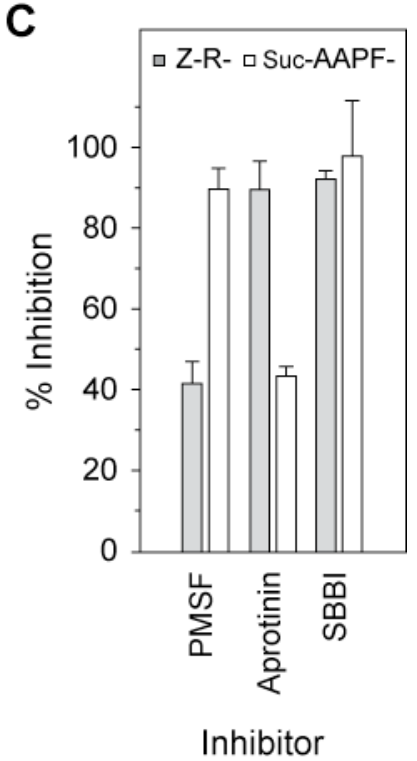

Figure 3. Cysteine cathepsin and serine protease activities in midgut protein extracts of banana weevil $3^{\text {rd }} / 4^{\text {th }}$-instar larvae. (A) Z-FR-MCA- (cathepsin L-like), Z-RR-MCA- (cathepsin B-like), R-MCA(aminopeptidase), Z-R-MCA- (trypsin-like) and suc-AAPF-MCA- (chymotrypsin-like) hydrolyzing specific activities. (B) Inhibitory effects of trans-epoxysuccinyl-L-leucylamido-(4-guanidino) butane (E64), Z-Phe-Tyr $(t \mathrm{Bu})$-diazomethylketone (Z-FY-DMK), L-3-trans-(propyl-carbamyl)oxirane-2-carbonyl)-Lisoleucyl-L-proline (CA-074) and different cystatins on cysteine cathepsin enzymes. (C) Inhibitory effects of phenylmethylsulfonyl fluoride (PMSF), bovine aprotinin and soybean trypsin-chymotrypsin inhibitor (SBBI) on trypsin-like and chymotrypsin-like enzymes. Assays were performed at $\mathrm{pH} 6.5$ for cysteine cathepsins and $\mathrm{pH} 8.0$ for trypsin and chymotrypsin. Each bas is the mean of three independent measurements \pm SE. 



Figure 4. Inhibition of banana weevil larval midgut cysteine cathepsins by recombinant (His) ${ }_{6}$-tagged variants of oryzacystatin I (OsCYS1) and papaya cystatin ( $C p C Y S 1)$. (A) Dose-response of Z-FR-MCA-hydrolyzing enzymes to OsCYS1 and $C p C Y S 1$ at $\mathrm{pH}$ 6.5. Data are expressed as residual activity following inhibition, compared to the activity of a non-inhibited control $(100 \%)$. Each datum is the mean of three values $\pm \mathrm{SE}$. The dashed lines indicate $I C_{50}$ values, defined as inhibitor concentrations required to reach a residual activity of $50 \%$. The inset gel is a Coomassie bluestained image of the purified cystatins following 15\% (w/v) SDS-PAGE. Mr, commercial molecular weight markers (kDa). (B) Stability of OsCYS81: and CpCYS1:banana weevil proteinase complexes submitted to non-reducing gelatin/SDS-PAGE. Proteinase (gelatinase) activities were visualized as clear lysis areas against a dark Coomasssie blue-stained gelatin substrate background after protease digestion (see Materials and methods). A low residual activity [i.e. no or little activity detected on gel] indicates a strong interaction [ $K_{\mathrm{i}}$ value in the nanomolar range or lower], and a high residual activity [i.e. with complete or partial restoration of activity] a weaker or negligible interaction [ $K_{\mathrm{i}}$ value in the micromolar range of higher] (Michaud et al., 1996a). Numbers on the left (P1, P2, P3, P4 and P5) refer to the insect gelatinases. Ctrl, non-inhibited control; BBTI, soybean Bowman-Birk trypsin/chymotrypsin inhibitor; EDTA, ethylenediamine tetraacetic acid. 
A



B

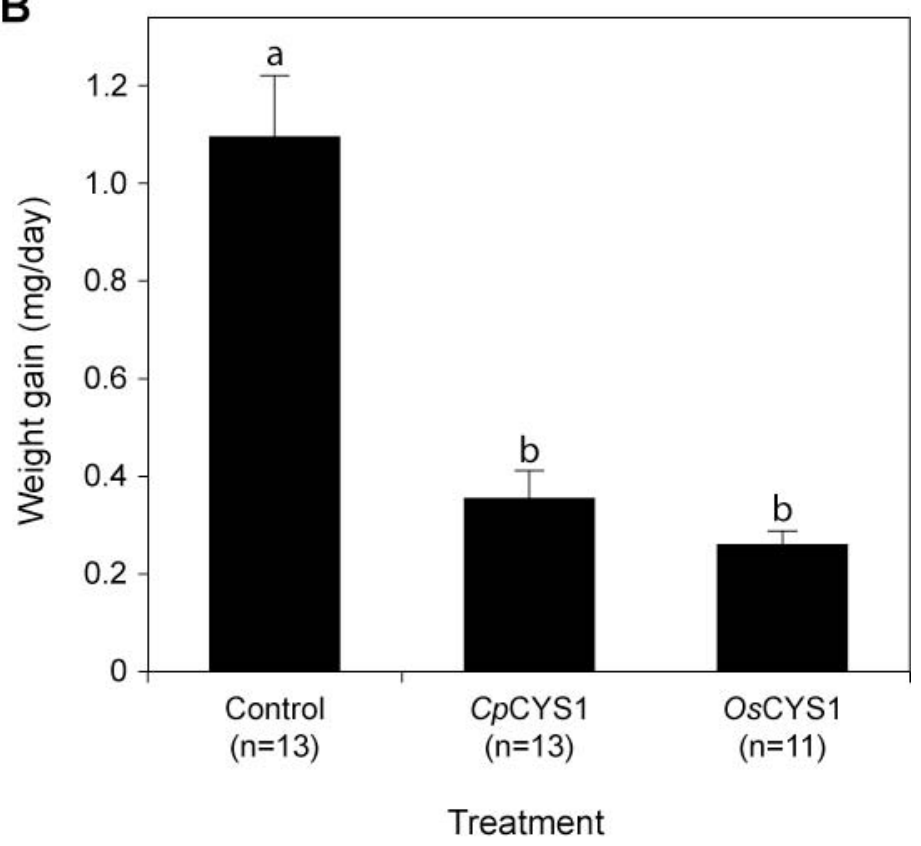

Figure 5. Impact of dietary cystatins on growth of newly hatched banana weevil larvae. (A) Larvae collected after 10 days from cystatin-free (control) (left) and OsCYS1-infiltrated (right) stem disks. (B) Daily weight gain of larvae developing in $O s C Y S 1, C p C Y S 1$ or cystatin-free (control) stem disks. Final cystatin concentrations after infiltration were estimated at $\sim 0.6 \mathrm{mg}$ per $\mathrm{g}$ fresh weight, as measured following protein re-extraction. Each datum is the mean of 11 or 13 values \pm SE. Means with the same letter are not significantly different (protected Fisher's LSD test; $P<0.01$ ). 


\begin{tabular}{|c|c|c|c|c|c|c|c|c|}
\hline Source species/Enzyme & Accession & Partial seque & ence & & & & & \\
\hline & & 90 & 100 & & 110 & 120 & & 130 \\
\hline HUMAN & & & & & & & & \\
\hline . Cathepsin L & $N M \_145918$ & SEESY . . . & $\ldots P Y$ & $\ldots$ & $\ldots$ & $\ldots$ & EATEESC &.$K \ldots \ldots Y$ \\
\hline - Cathepsin B & $N M_{-}^{-} 147783$ & SGGLYESHVG & $C R P Y$ & SIPPCE & HH VNGSRPPC & $T G$. & EGDTPKC & SKICEPG.Y \\
\hline . Cathepsin B/Mutant M1 & & SGGLYESHVG & CRPY & SIPP. . & $\ldots \ldots \ldots$ & $T G$ & $E G D T P K C$ & SKICEPG.Y \\
\hline COLEOPTERA & & & & & & & & \\
\hline - Tribolium castaneum & XM_969205 & TGGKYETKDG & CKAY & TVPPCE & HHTEGDLPAC & GD & IVPTPQC & KKECDAG.V \\
\hline & XM_969178 & TGGNYEDTNG & CKAY & SFAPCE & HHVDGDLPPC & GP & TKPTPDC & KKECDSG.S \\
\hline & $\mathrm{XM} \_969127$ & SGGSFGSNQG & CRPY & EIAPCE & HHVNGTRPPC & TGD & DNKTPSC & KQQCEKG.Y \\
\hline & $\mathrm{XM} \_961657$ & SGGDYNSNEG & CQPY & EGSA. . & $\ldots \ldots \ldots$ &. $\mathrm{FL}$ & NSVTPKC & STKCLNSKY \\
\hline & XM 963674 & SGGDYNTSRG & $\mathrm{CQPY}$ & SKSN . . & $\ldots \ldots \ldots$ &. $\mathrm{FN}$ & DGVSPEC & SKTCQNTKY \\
\hline & XM_969151 & SGGDLNSNEG & CRPY & TADA. . & $\ldots \ldots \ldots$ &. $\mathrm{HD}$ & KGVTPSC & TKS.RKG.Y \\
\hline - Diabrotica virgifera & AJ583509 & SGGQYGTKQG & CRPY & EIPPCE & HHTNGSRPAC & DAS & EGNTPKC & AKSCESN.Y \\
\hline . D. virgifera & AJ583513 & TGGLYGSKQG & CQPY & SLQPCE & HHTEGNKVQC & STL & DYDTPSC & KHKCDDS . . \\
\hline . Tenebrio molitor & DQ356051 & TGGLYGVDEG & CKAY & SIKPCD & HHVDGNLGPC & GDI & Q.RTPAC & KKSCDST.S \\
\hline . T. molitor & DQ356052 & SGGDVNSNEG & CRPY & TADA . . & $\ldots \ldots \ldots$ &. $\mathrm{HD}$ & QGQTPAC & TKSCRNG.Y \\
\hline - Callosobruchus maculatus & AY_429465 & SGGEYNSTNG & CMSY & PLPRCN & $\ldots \ldots$ PSC & KTL & . YDAPTC & KKECDKG.S \\
\hline
\end{tabular}

Figure 6. Two cathepsin B structural subgroups in the genome of Coleoptera. The partial sequences of human cathepsin B and selected cathepsin B-like enzymes from Coleoptera are shown, highlighting the occluding loop amino acid string (in grey box). A first group of cathepsin B variants includes enzymes with an occluding loop similar in size and primary structure to wild-type human cathepsin B, weakly sensitive to cystatins. A second group includes enzymes with a shorter loop, similar in size to the truncated occluding loop of the mutant M1, an engineered cathepsin B variant showing dramatically increased sensitivity to cystatin inhibition (Illy et al., 1997). The sequences were aligned using the MultAlin sequence alignment algorithm (Corpet, 1998), with human cathepsin B as a template for amino acid numbering. Conserved histidine residues interacting with the diagnostic cathepsin B inhibitor CA-074 are shown in bold. The corresponding partial sequence of cathepsin L is included as a control for the absence of an occluding loop. 